The Geneva Papers on Risk and Insurance, 19 (No. 71, April 1994) 127-134

\title{
Some Strategic Issues in the Insurance Industry Today
}

\author{
by Eugenio Coppola di Canzano*
}

\section{Towards a single European market}

\subsection{Objectives and freedom}

I have been invited to address you on some of the strategic issues facing the European insurance industry today.

Thank you for the invitation; in fact what I shall be attempting to put before you today is basically a description of a scenario in evolution, something that is still far from its final form.

You are doubtlessly aware of the extent to which recent failures with common monetary initiatives and differences in the approaches of partners to the reality of the single market have fuelled the scepticism of those who have doubts about Europe's ability to measure up as a Single Market to the other two giants, the United States and Japan.

You can, however, be certain that "unity" for Europe is not only a goal, not only a need, but has now become part and parcel of our approach to the future, even in insurance. And another thing most of us have long bean certain of insurance, like other economic sectors, would benefit by operating in a single market. From the very beginning, however, some wanted it "now", while others felt that the process had to be a very gradual one.

I am one of the oldest "servants" of the Generali Group, having worked for that institution since 1939: 55 years! I have therefore experienced from the inside the very origins of the idea of a single market, as well as the debate preceding the Treaty of Rome of March 1957.

30 years ago, I was very skeptical about the possibility of really homogenizing insurance in Europe. Take America, I used to say. They have a common language, a common currency, they are one Nation and yet they have chosen insurance not to have a unified supervision system nor freedom to provide transfrontier services from one State to another.

\footnotetext{
${ }^{*}$ Chairman and Managing Director, Assicurazioni Generali, Trieste.
} 
How can we think of achieving the goal of freedom of establishment and services without having first achieved in our multinational Europe some kind of uniform control system and uniform fiscal treatment for insurance?

I have been proved wrong! We are gradually achieving a homogeneous supervisory system and, even if we cannot expect in the foreseeable future any harmonisation of the fiscal treatment for insurance, we have largely achieved full freedom of establishment within the E.C. since the seventies and by July 1994 will complete the process of integration of our twelve regional markets into a single European insurance market operating with full freedom of services.

A long and progressive "intellectual" approach to the idea of a single market has been nevertheless necessary: We have had to "understand" the idea and its objectives... and have had to justify them to ourselves. In short we have had to modify our professional and cultural outlook.

And now, we have practically achieved our goal... We can now say that the main task is complete and that those four fundamental freedoms - concerning the circulation of persons, capital, goods and services - which were enshrined in the Treaty of Rome for all citizens and undertakings will be fully extended to the insurance industry by July 1994.

The twelve Member-States have accepted that an insurance company the Head Office of which is located in one "region" within the European market may quickly and freely establish branch offices in any other "region" of the EC and may offer and sell its "products" to persons and companies residing in any other "region" of the EC even without being established there.

Freedom of establishment and freedom to provide services are the goals inherent to the liberalisation of capital movements in the large markets. Together, they constitute a decisive step - taken at the beginning of the nineties - towards the integration of regional markets.

\subsection{From a common to a single market}

In the insurance industry, as in banking and financial services, consolidated national traditions and protectionism have delayed the European single market until now.

The prevailing speed-limit has meant our taking only one step every ten years.

a) The seventies sanctioned the right of all EEC insurance companies to establish themselves in any other "region" of the market on an absolutely equal footing with local businesses.

This eliminated the arbitrary nature of the administrative act of delivering a licence to do insurance business which was previously the responsibility of the Supervisory Authority in each of the twelve countries concerned.

b) In the eighties, a heated clash occurred between two schools of thought: the continental school - which is based on the idea that an insurer's activity cannot be separated from his "establishment" in the country of residence of his customers - and the Anglosaxon school, which is more flexible and allows for providing a service to the insured 
even from a different country, provided of course all the usual safeguards on solvency continue to be met by the insurer.

In line with the principles accepted by the twelve National Governments a "second generation" of E.C. Directives regulates the conditions* for doing insurance business by way of free provision of services to a first bracket of industrial policyholders who are deemed to be "mature" by reason of their adequate economic size - large and medium sized companies - and, therefore, fit to face the new market which became available to them beyond their national borders in July 1990 .

I wish, however, to stress that in order to maintain a clear distinction between the concurrent freedoms of establishment and of provision of services, an insurer operating under freedom of services will be forbidden to have recourse - for underwriting - to any permanent structure established in his customer's country; nevertheless, and only for the subsequent handling of policies and claims, the insurer may take advantage of such a permanent structure provided that the latter is charged on a "per service" basis.

c) The single insurance market for what are known as "mass" consumers, i.e. small companies and private persons, will be completed under the "third generation" E.C. Directives issued at the beginning of the nineties and which will have to be implemented and take effect by the 1st July 1994 in each national regulatory system.

\section{3. "Supervision" - the key-factors}

The three generations of Directives which I have briefly described, outline the final configuration of the single market and lay down rules to promote homogeneity in the pattern of financial guarantees required of insurers and in the action to be taken by Supervisory Authorities.

Let me briefly explain the main features of our single European market - Home Country Control of insurer's solvency, the "single licence", and non-systematic control of rates and policy conditions - achieved through relatively limited harmonization of national regulatory systems and through an adequate balance between control and freedom.

\subsubsection{Home Country Control and the "single licence"}

Full "Home Country Control" and the "single licence" mean that an insurance company, once duly authorized in its Home Office Member State, can set up Branches within the EC or provide cross-border services throughout the EC - as well as in most EFTA countries (Austria, Sweden, Norway...) as of 1st January 1994 - and, as regards its financial position, it will have to report only to the Supervisory Authorities from which it received its single licence, i.e. the Home Country Control Authority.

Administrative procedures to set up new establishments in other Member States or provide cross-border services will be very simple and tied to defined time limits.

* The definition of "provision of services" in insurance; in order to protect policyholders and insured persons, the EEC Court of Justice also stated in December 1986 (a) the need for a preliminary harmonization of national rules concerning technical reserves and relevant assets as well as of insurance conditions and (b) the prerequisite of an "authorization" from the Host Country Control in respect of "main risk" business only. 
According to the Third Non-Life Insurance Directive (92/49/EEC) and the Third Life Directive (92/96/EEC), the Home Country Control shall (a) communicate to the Host Country Control - within 3 months of receiving all the information from the Insurance Company intending to establish a Branch within the territory of another Member State - all the information received and concerning, inter alia, a scheme of operations setting out the types of business envisaged and the structural organisation of the Branch, and (b) attest that the insurance company possesses the minimum solvency margin.

Before the Branch starts business, the Host Country Controll shall - within two months of receiving all the information referred under (a) - inform the Home Country Control of the conditions under which, in the interest of the national "general good", that business must be carried out in the Host Country.

\subsubsection{Deregulation of rates and policy conditions}

Deregulation,... "surveyed" deregulation as finally achieved, represents the result of a search by member states for a balance between security for consumers and competition on products and premiums.

Traditionally, most Member States in the EC had in the past opted for a so-called "material" approach, concentrating not only on the financial position of the insurer - the primary objective - but very much also on a systematic, prior control of the insurance product itself, i.e. both the policy conditions and the premiums.

In some countries, such as the U.K. and the Netherlands, public intervention has traditionally been more limited allowing the insurer more freedom to define the products he intends to market. Control of insurance products has always been ex-post facto and nonsystematic, i.e. after the product has been marketed and on an ad hoc basis.

There are, therefore, two different approaches ... Member States have followed the Commission proposals and thus opted for the abolition of systematic, prior control of policies and premiums.

For those countries - like France, Germany and Italy - which traditionally applied prior, systematic control, these decisions imply substantial deregulation which will lead to a new balance between regulation and competition in their supervisory rules.

This is probably the most fundamental effect of the Third-Generation Directives. It is not surprising, therefore, that this issue was at the heart of the negotiations over these Directives. The E.C. Commission had always argued that the switch to ex-post facto, nonsystematic control was necessary to open up the Community's twelve largely segregated markets.

\section{The consequences for market participants. Insurers and intermediaries, supervisory authorities, consumers and competition rules}

In implementing the Third Generation E.C. Directives, member States will have to consider, and indeed are already considering, the consequences of this enhanced freedom for market participants. 


\subsection{Insurers}

This more competitive environment implies that markets - particularly those characterized thus far by strict product control - as well as their supervisors, will need to adapt.

This effort to adapt has been manifest over the last few years in a number of exciting initiatives aimed at acquiring new companies, and establishing joint ventures and agreements so as to increase presence in Europe as well as to promote exchange of know-how.

Markets will be more dynamic, more innovative and companies themselves will now be fully responsible "ab initio" for the products they develop and sell and no longer be able to rely, as in the past, on the prior consent of the supervisory authorities before marketing a policy.

We may expect a new generation of "European products" to appear on the European insurance market allowing the increased scope for product innovation promoted by the goal of the single market itself, and new trends in product evolution driven by the increased sensitivity of the social environment and consumer protection.

\subsection{Intermediaries}

Greater diversity in the products offered will also constitute a challenge for intermediaries.

Measures have been taken to ensure that insurance intermediaries will be adequately qualified. This was triggered by a Recommendation on insurance intermediaries issued by the E.C. Commission in 1991 with the aims (1) to lay down a minimum level of qualifications for all intermediaries, (2) to distinguish between dependent and independent inter." mediaries and (3) to organise registration for intermediaries.

The reliability of the insurance market depends upon the professional competence of insurers and intermediaries.

\subsection{Supervisory Authorities}

More dynamic markets also constitute a challenge for the supervisory authorities, who have to rely on different tools to do their job and will in general be obliged to follow market developments much more closely than in the past.

a) The scope of their responsibilities will broaden as they will have to "follow" companies in their cross-border activities within the large European single market, leading to an intensification of contacts with their colleagues in the twelve Member States.

b) Community Directives on financial services authorise - and partially regulate - investments and participation by an undertaking in one financial sector in an undertaking from the same or another financial sector.

As a result we may be witnessing increasingly pronounced diversification in the range of financial services offered, while the traditional boundaries between the types of financial products become blurred.

This raises new problems for the Supervisors of the three sectors, at the same time creating a strong need for cooperation among them.

c) As regards the asset side of the balance sheet, new "investment" products - such as derivatives (i.e. swaps, futures, options, etc.) - require attention. 
All of these examples illustrate that supervision is becoming a much more difficult task. This has been accepted by the twelve Governments and recognized at the E. C. level where action has been taken by creating the E.C. Insurance Committee, a Community body providing a platform for effective cooperation between supervisory authorities and serving as a high-level advisory body to the E.C. Commission.

\subsection{Consumers}

For consumers, the internal market should lead to a wider choice of products, competitive pricing and better servicing.

There may, however, be an apparent loss of transparency for individual consumers in countries where product control has always been very strict resulting in a relatively limited number of products being "on sale". Without underestimating the importance of this issue, I think that one can be confident that markets themselves will react when there is a demand for more transparency.

Consumer organizations, the press, or independent brokers may traditionally play a relatively more prominent role in innovative markets because there has been a more explicit demand for independent advice.

\subsection{Competition rules}

The strict general rules enshrined in the Treaty of Rome to safeguard free competition are tailored to the specific features of the insurance industry where ordinary production cycles are totally reversed. Unlike all other businessmen, insurers must price their products according to an estimate of future cost, i. e. the cost of claims. Accordingly, statistics are of vital importance in narrowing the gap between forecast and facts.

In a special Regulation of 1992, the E. C. Commission has therefore recognised, on the one hand, the need for statistics to be collected and processed jointly by several insurance companies - thus legitimatizing calculations to define the net cost of insurance services, i.e. net premiums - and on the other the usefulness of pools as companies find it necessary to pool their economic resources and technical know-how to cover certain risks.

In Europe we have experienced the negative effects of competition not anchored to technical supports and references, but driven instead by the trend to buy up market share in order to approach the single market in a position of priority. This brought difficulties for many insurance companies : some faced deep crisis, some went bankrupt.

We are in fact convinced that it is both essential and urgent to go back to a technical approach, now that the illusion of the omnipotence of finance has been proved wrong and, for those operating on an international level, to realise that the alternation of asynchronous cycles can no longer be relied upon.

\section{Final remarks}

3.1. In July 1994, the European Community with a share of about $30 \%$, will be in a commercial position comparable to that of the other two big traditional markets - the United States $(34 \%)$ and Japan (22\%) : together these three will cover more than $85 \%$ of the world market. 
With insurance penetration levels at $8.6 \%$ of GDP in the USA and $8.5 \%$ in Japan, Europe with its $5.9 \%$ level has significant growth potential while the other two markets are experiencing stagnation or even recession.

Moreover, we should not lose sight of the fact that Europe is evolving towards the idea of privatization of the health service and of social security.

3.2. The Generali Group has already completed procedures to gain access under freedom of services - at present for underwriting both Life and Non-Life "large risks" - from each of its Branches and Subsidiaries in Europe to each of the twelve "regions" in the single market. Right here, in the European single market, our Group through its own establishments has a practically unrivalled ability to provide a direct ongoing service, which, together with solvency, is currently a "sine qua non" in the insurance business.

We are firmly persuaded that the single market will substantially change the way services are provided to small and medium industries, which are becoming increasingly international and which, therefore, will expect insurers to be able to manage their interests beyond national borders. This is an interesting category of customers, accounting for approximately $30 \%$ of the non-life insurance market.

The situation could be different in the case of private customers, who will probably continue to look - at least for non-life insurance - to insurers established in their own country and providing locally "custom-made" services.

From Lisbon to Athens, from Dublin to Paris, from London to Amsterdam, from Trieste and Brussels to Munich and Madrid, our historically established Branches and Subsidiaries operating within each European region are now allowed to operate under freedom of services across the entire single market, beyond, that is, their traditional "regional borders".

These same opportunities are equally open to any European insurer and to US insurers' Subsidiaries established within our "single market". The British subsidiaries of INA, Insurance Company of North America, and CIGNA are already authorised to operate under freedom of services from the United Kingdom towards any other subsidiary within the single market...

On the basis of reciprocity with Third Countries, European policy is not to close Europe off but increasingly to open it up.

The opening-up of the traditional regional markets in Europe and their integration into a single market - which itself becomes in turn open to the other two giants - creates one crucial prerequisite : the hard task, that is, for insurers to know their real technical costs as well as to control and to track the handling and distribution costs of their products in order to offer a service where "quality" may be consistent with price.

More sophisticated instruments will be required for the assessment and rating of risks which become even in terms of "size" increasingly complex: ... I need only mention the example of public liabilities risks, large industrial risks and those linked to the atmospheric events from which we all have suffered as insurers.

3.4. Last year in Vienna, we already discussed these very problems during a Seminar on Risk Management. We insisted on the need for cooperation between insurance and industrial undertakings, as well as for new legislation, to help define an acceptable profile for "insurable risks" so as to enable insurers to do a better job. 
Over the last two decades, Generali, as leading insurer in Italy, has promoted biennial Conventions with the Ministry for Industry and the "Confindustria" - The Italian Manufacturers' Association - aimed at improving insurance coverage to reflect the growing needs of manufacturers, on the basis of rates for our industrial customers which are technically appropriate and economically affordable.

3.5. But that is not enough! Even if the productivity of European insurers has substantially improved over the last ten years, we stand today at a turning-point: We need a complete rethink of our production cycle - a break with the past - perhaps even a quantum-leap into the future in further reducing the impact of our costs and in keeping our products cheaper.

The harmonization of regional regulatory systems in accordance with the EC Directives will be helpful in further standardizing operational procedures, to be implemented through a review of computerized systems and massive use of telecommunications.

We at Generali are so persuaded of these needs, that we are thoroughly reviewing our production cycle and have set up a network of interconnected computerized centres in the main European capitals.

This new scenario requires human resources which are highly skilled and sensitive to the internationalisation of the old regional markets. That is why we have founded a school where the most able employees from our European and non-European Branches and Subsidiaries can meet and receive systematic training and be constantly up-dated on developments across the single market.

Europe is a difficult but interesting market, as much in terms of its size as of its capacities.

In Europe, countries which have built up and consolidated their identity over the centuries, with different languages, cultures, laws and currencies, are now having to search out and find a balance between the general interest and their individual needs. What the Roman Empire, Charlemagne, Charles V and the Habsburgs had been unable to impose, is now being achieved out of free choice.

But let us not fool ourselves.

The next steps are not going to be easy, and a further period of patient adjustment will be necessary. But a pragmatic approach to solving problems in a "Community spirit", as they arise, should prove fruitful in enabling the E.C. to develop a truly single and cohesively regulated market for insurance. 